\title{
Conquering the digital divide: Botswana and South Korea digital divide status and interventions
}

\author{
Authors: \\ Nonofo C. Sedimo \\ Kelvin J. Bwalya ${ }^{2}$ \\ Tanya Du Plessis ${ }^{3}$

\section{Affiliations:} \\ ${ }^{1}$ Department of Library \\ and Information Studies, \\ University of Botswana, \\ Gaborone \\ ${ }^{2}$ Center for Information and \\ Knowledge Management, \\ University of Johannesburg, \\ South Africa

\section{${ }^{3}$ Department of} \\ Information and Knowledge \\ Management, University of \\ Johannesburg, South Africa \\ Correspondence to: \\ Tanya du Plessis \\ Email: \\ tduplessis@uj.ac.za \\ Postal address: \\ PO Box 524, Auckland Park \\ 2006, South Africa \\ Dates: \\ Received: 24 Jan. 2011 \\ Accepted: 25 July 2011 \\ Published: 08 Nov. 2011 \\ How to cite this article: \\ Sedimo, N.C., Bwalya, K.J. \\ \& Du Plessis, T., 2011, \\ 'Conquering the digital \\ divide: Botswana and South \\ Korea digital divide status \\ and interventions', SA Journal \\ of Information Management \\ 13(1), Art. \#471, 10 pages. \\ http://dx.doi.org/10.4102/ \\ sajim.v13i1.471
}

(C) 2011. The Authors. Licensee: AOSIS OpenJournals. This work is licensed under the Creative Commons Attribution License.
Background: Botswana is putting in place initiatives towards establishing itself as a knowledgebased economy. Transformation from a resource-based to a knowledge-based economy is partly hinged on innovation, research and development capability, knowledge channels, and the funding of research and development activities.

Objectives: Bridging the digital divide and narrowing the intra-national divide brings about global information and communication technology (ICT) usage that translates into changing work patterns and eventually transformed economies. This article outlines the different interventions implemented in Botswana to bridge the divide. The South Korean experience in bridging the divide is discussed so as to serve as lessons on how to effectively bridge the divide to Botswana's initiatives.

Method: Using a mix of exploratory and empirical study, this article presents the findings on the status of ICT uptake in Botswana and investigates the level of the digital divide in the country.

Results: The results of the study show that the digital divide is much more evident in Botswana than in South Korea. South Korea has put in place robust strategic initiatives towards reducing the digital divide and this has largely transcended into its transformation into a full-fledged knowledge society.

Conclusion: This article is timely as it unearths the different pointers that may be utilised in policy formation and what interventions need to be taken at both the individual and national level to bridge the digital divide.

\section{Introduction}

The digital divide presents itself as a roadblock to socio-economic development in different regions and countries. With the presence of the digital divide, many opportunities offered by the digital revolution such as online job search, efficient information management (IM), online social networks and electronic mail systems cannot be accessed. At a national level, it is possible that a country may fail to benefit from the returns of the global socio-economic value chains if there are blatant levels of digital divide. In this article, the concept 'digital divide' refers to the difference in access and usage of information and communication technologies (ICTs), and correspondingly to information content and any socio-economic opportunities such as jobs, social inclusion and tribal and/or regional integration.

Understanding the extent of the digital divide is vital as access to ICTs is now commonly looked at as the fons et origo of contemporary innovation practices. There are basically two kinds of digital divide. The first kind is the 'vertical divide', which outlines the gap between users and non-users of information technology (IT). This is considered the first level of the divide and it presents the problem of unequal opportunity to efficient access of information resources. The second type of divide is the 'horizontal divide', which outlines the gap among IT users. This is correspondingly considered the second level of the divide and it presents the problem of social integration and inclusiveness. It is worth mentioning that the digital divide is a complicated phenomenon that hinges on many different factors (James 2009). This article investigates these two types of the divide at the intra-national level of Botswana.

Botswana has recognised that in order to compete favourably in the global economic value chains, it requires a national focus towards transforming from a resource-based economy to a knowledgebased economy (KBE). A KBE involves codification of knowledge (using knowledge engineering and knowledge management) in different socio-economic sectors with a view of differentiation towards a competitive edge. In a KBE all the measures of production and productivity as well as 
innovation are fueled by knowledge. A KBE is attained when a country effectively participates in the 'information society' where knowledge is utilised in all the socio-economic value chains. The attainment of a KBE entails that a country is going to be placed at a competitive edge in global business value chains. This recognition has been compounded by the following pronouncement in Vision 2016: 'Botswana aims to be a prosperous, productive and innovative society; an open democratic and accountable society; and an educated, informed society' (Hall \& Lewin 2005:20).

Any aspiration to transform towards a KBE cannot be achieved without the efficient use of ICTs. Under the current dispensation of the Vision 2016, using different forms of ICTs is recognised as a major cornerstone towards achieving a competitive economy. Botswana's ICT sector development has ushered in a paradigm that promotes efficient information and knowledge management through the use of ICT platforms. This is a cardinal milestone towards establishing an economy where the emphasis is on the effectual management of knowledge despite economies of scale of production and other business management strategies, including six sigma, and despite earlier economics researchers' theories such as Frederick Winslow Taylor (1911-1915) in his theory of scientific management (Serrat 2010:139, 153, 163-165).

Transforming from a resource-based economy to a KBE requires an understanding of present economic and noneconomic indicators of the digital divide. The economic indicators include the financial cost of acquiring access to ICT tools and platforms such as mobile phones, computers and the Internet. The non-economic indicators are divided into social, cultural and opportunity cost of not engaging in ICT usage, and technical indicators such as the level of individual ICT literacy skills and usability of the ICT platforms. To shed some light on these indicators, this article firstly presents background information on the phenomenon of the digital divide by providing more theoretical underpinnings, followed by the empirical study. Secondly, the different approaches in addressing the digital divide in Botswana and South Korea (henceforth, Korea) are presented respectively. This is followed by an analysis of the gaps in the status of the digital divide in Botswana and Korea to determine the lessons learnt from these experiences. Korea has been chosen to showcase how the massive integration of ICTs into various socio-economic value chains can improve the innovation potential of a nation. Currently, Korea is the leader of consumer electronics and e-Government development, and also occupies a top spot in Digital Opportunity Index (DOI) worldwide (UNDESA, 2010). It is thought that a closer look at Korea may serve as lessons to Botswana as it intends to bridge its massive digital divides.

By using the current socio-economic indicators, the two countries are not comparable. However, comparison is necessary as in 1966, when Botswana achieved its independence, both countries had socio-economic indicators that were within the range of comparison. Currently, both countries have a dedicated leadership that is committed to enabling all citizens to have equal access to information; both aim to participate effectively in the information society and reduce dependency on natural resources, and both have comparatively high literacy rates. Just like Korea with its limited natural resources, Botswana is also devising plans to diversify from over-dependence on diamonds to being innovative in various other sectors of the economy. This can be accentuated by its plans to establish the Botswana Innovation Hub (BIH) and the already established Botswana Productivity Center (BPC) to drive the national innovation and competitiveness agenda. In order for this to be achieved, access to information through global usage of ICTs such as computers and the Internet is desired. Korea's brilliance in emerging as a global leader in as far as broadband and Internet penetration is concerned can serve as a lesson to Botswana. It is not the intention of this paper to compare Korea and Botswana one-on-one but to highlight Korea's experience as a reference point for effective design of digital divide interventions.

Korea is a transitional economy that has higher Internet and broadband penetration rates than Botswana. In the not too distant past, Korea was a developing country with no tangible natural resources but with a promising human resource base. Botswana has a middle-income economy that is showing a lot of potential to bridge the massive digital divide gaps amongst its population so that it can later participate effectively in the information society. The economic prowess of Korea is hinged on the rigorous exploitation of consumer electronics (such as Samsung, LG electronics), the automobile industry (such as Hyundai, Daewoo, KIA) and the shipbuilding industry. Korea has a Gross Domestic Product (GDP) of \$1338 trillion (Gambrill 2010), a literacy rate of 99\%, a GDP per capita (purchasing power parity) of $\$ 20000$, a population of 48520835 (Kettani 2010) and a land surface area of $98444 \mathrm{~m}^{2}$ with over 443000 $\mathrm{km}^{2}$ of marine area and about $12000 \mathrm{~km}$ of political borders defined by maritime boundaries. Botswana has a land area of approximately $582000 \mathrm{~km}^{2}$ (Mathuba 2003), a population of 1.99 million, a GDP of $\$ 15.2$ billion and a GDP per capita of about $\$ 14800$.

Of the possible ICTs that may be utilised to access information resources, this study probed participants' access to computers and correspondingly the Internet. Access to the Internet through other convertible modes such as mobile phones was also considered. The study intended to investigate the vertical and horizontal divides, in other words, access to information through the Internet. The investigation of the extent of the digital divide also involved analysing the ICT policy and institutional frameworks, the tele-density, broadband and Internet penetration, and the actual access and usage of computers and the Internet. The study also contained an empirical part for Botswana in a view to probe and emphasise the actual status of the divide at the individual level. 
Since Korea has achieved very high broadband and Internet penetration rates, it can be used as reference points when devising strategies for global ICT penetration and mitigating the extent of the digital divide. This article provides guidance on how policy should be framed, for the case of Botswana, by indicating which interventions have been implemented to encourage Internet penetration in Korea.

\section{Background}

Many researchers have investigated the impact of the digital divide and the value of information on different endeavors to transform economies into KBEs. In the contemporary world, information is viewed as a dematerialised economic entity and is correspondingly used as a measure of power (Bassey 2008). Information brings about convergence of a variety of social norms and the codification of information in a manner that it enables ideas to be shared easily and cheaply. This characteristic of information makes efficient management of information a prerequisite to establishing a KBE.

Countries with developed economies have shown that appropriate utilisation of ICTs in different socio-economic sectors comes with a 'leapfrog effect' in as far as development is concerned (Mansell 2001). The 'leapfrog effect' is a term that has been utilised in this context to show that effective and proper utilisation of ICTs may result in revolutionary or instantaneous rather than incremental effect (or ripple effect) on a country's development. Efficient use of ICTs in enterprises will translate into greater productivity (Bresnahan, Brynjolfsson \& Hitt 1999). This efficient use of ICTs can only be ushered in when there is good political will to encourage proliferation of ICTs in all socio-economic sectors. The preceding comment was confirmed by James (2002) who posits that there is substantial evidence that emerging democracies such as South Africa and Brazil have leapfrogged in their adoption, synthesis, integration and application of digital technologies. This may point to the assertion that appropriate digital diffusion requires fertile ground for democratic development.

A lack of appropriate IM channels may limit information flow and therefore impact on productivity at both enterprise and individual levels. The World Bank Report (2000) suggests that disparities in the productivity levels may be attributed to poor telecommunications infrastructure and practices in most of the African states. An empirical case of this assertion is that of Zimbabwe and Botswana where 'areas with high levels of resources and skilled labour but with lower levels of telephony have fewer 'productivity enterprises' (Robison \& Crenshaw 2000:5). This may not be exhaustive but presents a clue as to how ICT infrastructure plays an indirect role on impacting on economic growth. Effective utilisation of ICTs will enable enterprises to pursue blue oceans, viz 'the unserved market, where competitors are not yet structured and the market is relatively unknown' (Hollensen 2007; cf Kim \& Mauborgne 2004; Burke, Van Stel \& Thurik 2010:28). This is especially the case for countries with developing economies; ICTs will enable them to appropriately market their natural resources, which may culminate into an increase in foreign direct investment (FDI).

The digital divide negatively affects FDI (Fuchs \& Horak 2008:109). Unequal access, adoption and usage of ICTs result in limited access to information resources. When this situation is evident, we say the digital divide exists. Researchers agree that 'digital divide' is the metaphor used to 'describe the perceived disadvantage of those who either are unable or do not choose to make use of information technologies in their daily life' (Cullen 2003:247). The digital divide has also been defined as 'the strikingly differential extent to which rich and poor countries are enjoying the benefits of information technology' (James 2003:25) and as 'the unequal distribution of computers, Internet connections, fax machines and so on between countries' (James 2003:23). James (2009:25) further describes the digital divide as the differentiation that comes about with benefits reaped from use of ICTs by both the rich and poor countries. Campbell (2001) simply defines the digital divide as a situation in which there is a clearly identified gap in the access or use of ICT platforms. This gap can be looked at as the 'haves' and 'have-nots' with reference to people with or without access to ICTs (Chon 2001; Cronin 2002). The digital divide, which presents itself as a gap between information haves and have-nots, is evident amongst different groups in the same country, referred to as 'intra-national digital divide'; and between countries, referred to as 'global digital divide' (Ono 2005). Wilson (2006:300) concludes that the digital divide is 'an inequality in access, distribution, and use of information and communication technologies between two or more populations'.

The digital divide is not only linked to Internet access but also to its usage attributes such as ease-of-use (usability) and overall benefit (Fuchs \& Horak 2008). The Organisation for Economic Co-operation and Development (OECD 2004) posits that the digital divide includes factors such as education and literacy, income, ICT skills, marker structures, institutional frameworks, and competition. Apart from associating the digital divide with the provision of computer connections and the Internet, it also encompasses a complex array of factors such as human, digital, physical and social relationships (Warschauer 2001). Norris (2001) defines the digital divide as being multidimensional in nature. It includes different versions such as global, social and democratic digital divide. The International Telecommunications Union (ITU 2005:vii) ascertains that the digital divide highlights the uneven distribution and differences or gaps that exist in opportunities to access and the use of ICTs amongst diverse population groups, be they individuals, households, businesses, institutions or geographical areas.

Having defined the different aspects of the digital divide, it is necessary to show the levels of access and usage of Internet in Botswana as compared to different African countries. This is important to show how Botswana fares when compared to other countries with the same socio-economic conditions. Table 1 shows the ICT use and penetration status in three 
TABLE 1: Internet users and population statistics for specific countries.

\begin{tabular}{|c|c|c|c|c|c|c|}
\hline \multirow[t]{2}{*}{ Africa } & \multirow{2}{*}{$\begin{array}{l}\text { Population } \\
\text { (2009 Est.) }\end{array}$} & \multicolumn{2}{|c|}{ Internet users } & \multirow{2}{*}{$\begin{array}{c}\text { Penetration } \\
\text { (\% population) }\end{array}$} & \multicolumn{2}{|c|}{$\%$} \\
\hline & & Dec. 2000 & Latest data & & User growth & Total users in Africa \\
\hline Angola & 12799293 & 30000 & 550000 & 4.3 & $1733.30 \%$ & 0.6 \\
\hline Botswana & 1990876 & 15000 & 120000 & 6.0 & $700.00 \%$ & 0.1 \\
\hline Burkina Faso & 15746232 & 10000 & 140000 & 0.9 & $1300.00 \%$ & 0.2 \\
\hline
\end{tabular}

Source: Internet World Statistics, 2010, Internet users and population statistics for specific countries, viewed 16 August 2011, from www.internetworldstats.com Note: The user growth data is for the period 2000-2009.

African countries, Angola, Botswana and Burkina Faso, and the growth in Internet users from 2000 to 2009 in each country.

From Table 1, it can be shown that Botswana has only 120000 people actively using the Internet accounting for $0.1 \%$ of the total users in Africa. It is evident that Internet penetration has to increase for Botswana to fully participate in the knowledge economy, to model an information economy, or to develop into a knowledge-based economy.

In general, different models of the information and/or knowledge-based economies may be applied at the urban level to measure the intra-national digital divides, and between and within regions (Van der Meer \& Van Winden 2003; Venturelli 2002). Using countries as the unit of analysis for the digital divide, the ITU (2006) carried out a study to ascertain the level of the digital divide between the countries with developed economies and those with developing economies. Table 2 shows the digital divide with reference to mobile phone subscription from 1998 to 2004 in two broad categories, namely, so-called 'developed' and 'developing' countries.

Table 2 presents a significant decrease, albeit in relative terms, with regard to the digital divide. This is in line with the prediction of Norris (2001), namely that with time, the digital divide would decrease as more and more people will have access to ICTs. This line of reasoning is premised on Moore's Law, viz, that the number of transistors on integrated circuits and hence processing power doubles every 18 months while the costs do not increase. Whether this reasoning holds true to Botswana and the digital divide is further investigated in the empirical study discussed in the next section.

The empirical part of the paper aims to show the proportion of people who may be 'information rich' versus those who may be 'information poor' in Botswana owing to their lack of efficient access and usage of ICTs. It is assumed that ICTs may facilitate access to essential information at any time and promote effective and informed decision-making, improve innovation and correspondingly promote competitiveness.

\section{Empirical study}

Botswana is currently putting in place initiatives towards establishing itself as a KBE (Hall \& Lewin 2005:20). Transformation from a resource-based to a knowledgebased economy is partly based on innovation, research and development capability, knowledge channels, knowledge solutions, and the funding of research and development

activities (Serrat 2010). Narrowing the intranational digital divide brings about global information and communication technology usage that translates into changing work patterns and productivity growth. This section presents the findings of the empirical study on the status of ICT uptake in Botswana and investigates the level of the digital divide in the country.

In an attempt to understand the extent of the digital divide in Botswana, both a literature review and a document analysis were done. The literature and document analysis aimed at understanding the different interventions that have been done to bridge the digital divide. The empirical study aimed at understanding the actual divide at the individual level thereby investigating the vertical and the horizontal divides.

A questionnaire with both open and closed-ended questions was utilised in this study. This questionnaire was pilottested with 10 participants to establish its face validity, test its reliability and improve the clarity of the questions so that participants may comprehend it with ease (in conformance with Creswell 1994). It was important to establish the reliability of the data collection instrument so that errors and biases were eliminated as much as possible (Yin 2003). Measuring the validity of the questionnaire was important to make it possible for correct and authentic data to be collected and later appropriately subjected to correct empirical analysis (Luk 2009). Open-ended questions ensured that there were no restriction on how a respondent could answer questions and presented an opportunity where participants' opinions on probed phenomena could not be answered using pre-defined categories (Wilson 1996). Alternatively, closed-ended questions come with many options out of which a respondent is mandated to choose one or more of them relating to his or her experience about the phenomenon under investigation (Saunders et al. 2002).

The survey, conducted in 2010, was aimed at exploring the use of ICTs by citizens of Botswana. The study specifically aimed at understanding whether ICTs are being utilised to access essential information or utilised to ease peoples' daily activities. In so doing, the study wanted to understand the

TABLE 2: Digital Divide from 1998-2004.

\begin{tabular}{lcc}
\hline Type of country & Mobile phone subscribers per 100 persons \\
\cline { 2 - 3 } & $\mathbf{1 9 9 8}$ & $\mathbf{2 0 0 4}$ \\
\hline Developed & 24.6 & 76.8 \\
Developing & 1.9 & 18.8 \\
Size of digital divide (relative terms) & 12.9 & 4.1 \\
\hline $\begin{array}{l}\text { Source: International Telecommunications Union, 2006, Statistics, International } \\
\text { Telecommunication Union, viewed 02 September 2011, from www.itu.int/ITU-D/ict/ } \\
\text { statistics/ }\end{array}$
\end{tabular}


impact of ICT usage on some aspects of the digital divide. A random sampling technique was utilised in this research targeting people with different levels of education and exposure to ICTs.

To be included in the study, participants had to be at least 21 years old, have completed high school, and have potential and requisite ICT skills to effectively utilise ICTs in their daily endeavors. Out of this group, there were participants who chose not to utilise ICTs (non-users) because they thought the perceived value was low. These were compared with the participants that utilised ICTs thereby obtaining a subjective feeling of the extent of the divide (vertical divide). Amongst the active users, qualitative analysis of the difference functions for which they utilise ICTs was also subjectively measured (horizontal divide). Because of resource constraints, all the respondents were drawn from Gaborone. Over 50\% of the respondents were women aged between 25 and 36 years old. This is important because it shows that the study employs gender inclusiveness.

The catchment area for the project was Gaborone (capital city of Botswana). Specifically, data was collected from faculty and students from the University of Botswana, workers from the Ministry of Education, Mascom Wireless Company, and the Botswana Council of Non-Governmental Organisations (BOCONGO). The study utilised a short questionnaire comprising only seven questions. The sample frame included 153 people. Eventually, a total of 119 people participated in the survey. Of these, 62 were women (52\%) and 57 were men $(48 \%)$. The study targeted individuals who utilise ICTs in their day-to-day activities. Prior to being involved in the study, potential participants were asked whether they have the necessary ICT literacy levels to potentially engage in ICT usage. The majority of the study was conducted at the University of Botswana where a total of 87 questionnaires were distributed to the respondents and only 61 (70\% response rate) were included in the final analysis. At Mascom Wireless Company, 15 questionnaires were distributed and 14 (93\% response rate) were returned for analysis. At the Ministry of Education, 46 questionnaires were distributed and 39 of them were returned for analysis (85\% response rate), and at BOCONGO 6 questionnaires were distributed and 5 were returned for analysis ( $83 \%$ response rate).

The first question requested respondents to provide information on the frequency with which they use ICTs on a daily basis. The options were, 'Never', 'One to three times' and 'More than three times'. The majority of respondents, $83.5 \%$, indicated that they use ICTs more than three times a day, whilst $6.5 \%$ of respondents mentioned their frequency of ICT usage between one to three times per day. Of the respondents, $10 \%$ indicated that they have the requisite ICT skills but do not use ICTs at all in their day-to-day activities at work apart from checking e-mails.

The second question requested respondents to provide information on their different uses of ICTs. Figure 1 illustrates respondents' reasons for using ICTs, with communication and data ranking the highest, followed by other uses such as work, entertainment, e-Commerce and school work.

The third question required respondents to provide information on the value that the use of ICTs adds to their daily routines. Respondents had to rank the value they experienced from using ICTs in terms of personal development, easy access to information, saving time, convenience, speed with which work is done and economical value. The results are shown in Figure 2. Respondents mostly perceived the value of using ICTs on a personal development level.

The next question expected respondents to specify if they preferred automating daily routines with the use of ICTs or not. Responses were limited to the options 'Yes' and ' $\mathrm{No}^{\prime}$. Only $10 \%$ of the respondents chose ' $\mathrm{No}^{\prime}$, whilst $90 \%$ of the respondents said they preferred automating daily routines with the use of ICTs.

Question five requested respondents to specify whether the use of ICTs increases their access to personal and professional information. They had a choice to choose between 'Yes' and 'No'. In opting for ' $\mathrm{No}^{\prime}$, respondents were also expected to give reasons for their choice. All the respondents chose 'Yes', thereby indicating that the use of ICTs is seen to positively facilitate access to personal and professional information.

Question six required respondents to indicate the challenges that they face when attempting to access ICTs. Respondents had the choice to select more than one option from the following list:

- low bandwidth

- lack of ICT skills

- lack of security

- high cost of ICTs

- lack of ICT resources

- operations failure.

The responses are presented in Figure 3, with low bandwidth and lack of ICT resources perceived by respondents as the two major challenges to accessing ICTs.

The answers to six of the seven questions asked indicate a high usage of ICTs, with the daily use of ICTs being the norm. This amplifies the fact that ICT are an important component in today's socio-economic environment. The majority of this survey's respondents use ICTs for communication and data manipulation. There was also a high indication that people use ICTs for work related purposes and entertainment. Most respondents perceived the use of ICTs as beneficial to their personal development. Other perceived advantages of ICT usage include that it helps save time, increases speed with which work is done and convenience. These factors can be translated to higher productivity levels. Despite this being the case, yet others still found ICTs not to be of any value preposition. 


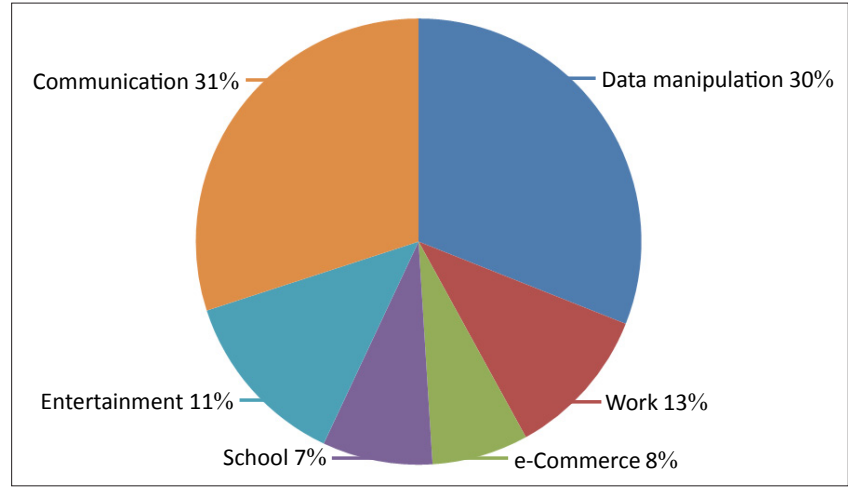

FIGURE 1: Uses of information and communication technology (ICTS).

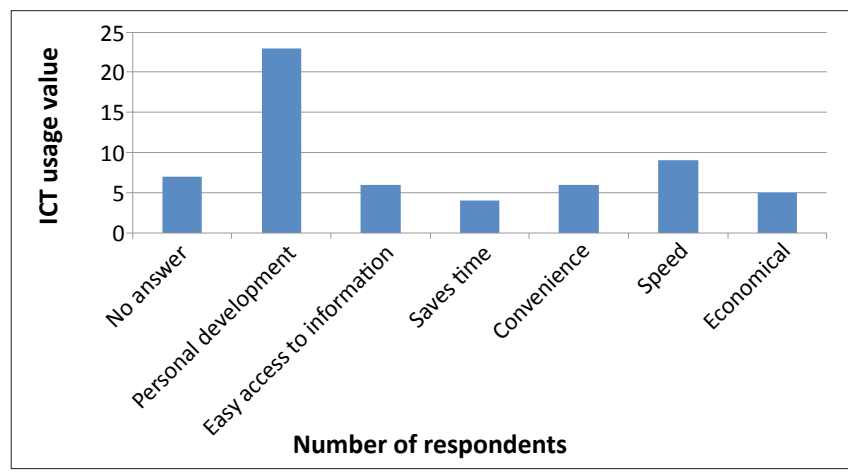

FIGURE 2: Value added by the use of information and communication technology (ICTs).

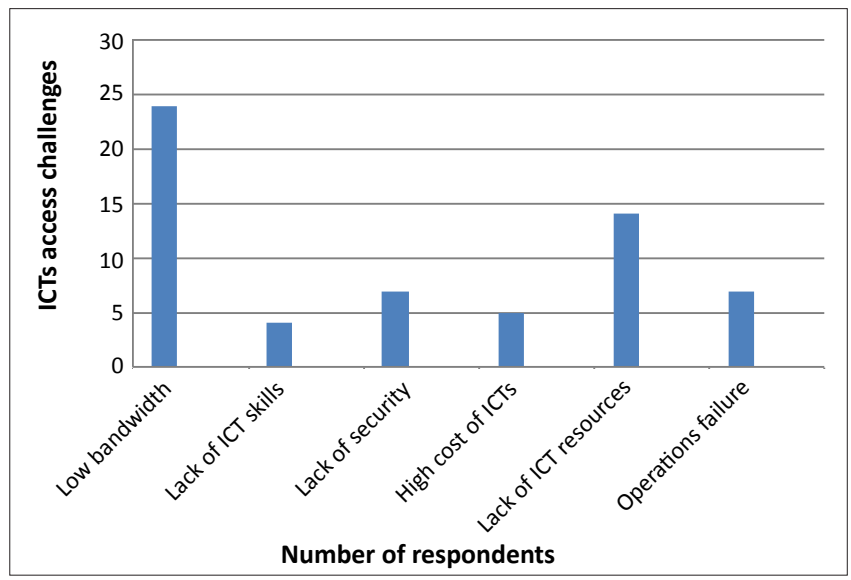

FIGURE 3: Challenges in accessing information and communication technology (ICTs).

The majority of respondents indicated that they would prefer to automate their daily routines with the use of ICTs. Those respondents who refrained from such automation cited reasons such as low ICT skills, and trust and usability issues as being the major challenges. All participants agreed that ICT usage facilitates information access and efficient management of personal and professional information. The general challenges that participants faced in accessing ICTs are associated with a lack of basic ICT skills on their part, unavailability of readily accessible ICT platforms, security, and operation failure issues. Specific notice should also be taken of the main challenges that were identified, namely, low bandwidth and lack of ICT resources.
Finally, the respondents were asked about their knowledge on the different digital divide interventions that are currently in place in Botswana. Respondents indicated that they had some knowledge on what the government is currently doing to address the ICT related challenges. However, respondents mostly do not know what the government is doing to address their problems in ICT usage. Most of the respondents recommended that in order for the government to leapfrog the campaign to bridge the digital divide, there is a need to look more into ICT education, lowering ICTs costs and improving electronic service delivery. There is also an outcry for industry revolution and the provision of ICTs resources. From these responses, it is clear that the intra-national divide is very evident in Botswana.

The status of the digital divide (demand side of ICT access) in Botswana, as presented earlier in the article, may reveal some gaps in the effectiveness of the various interventions put in place to address the divide. In the next section a discussion follows regarding the different interventions that have been established in both Botswana and Korea. This will allow us to identify the gaps in these different interventions (supply side of ICTs) and shed some light on what should be done in the case of Botswana with full consideration of the local context. As mentioned earlier in the article, there currently is no outright similarity between Korea and Botswana but this comparison is done to assess the impact of robust interventions in ICT access and usage promotion, and what impact this has on the overall digital divide. Botswana (with a GDP per capita of $\$ 57.97$ in 1960) and Korea (with a GDP per capita of $\$ 156$ in 1960) now have GDP per capitals of $\$ 13$ 100 and $\$ 30200$ respectively (CIA 2011). This massive growth of GDP in the case of Korea is attributed to the role of ICT on general economic growth and the increase in productivity and innovation amongst the different enterprises and businesses (Yoon, Na \& Jung 2009). To compare the level of ICT adoption and the extent of the digital divide between Botswana and Korea, document analysis was done to establish what interventions have been done on the supply side to encourage global ICT access and usage and therefore reduce blatant intranational digital divides.

\section{Botswana and Korea digital divide status and interventions \\ Botswana}

The status of Internet adoption in Botswana can be established by assessing the latest figures released by the ITU and the Botswana Telecommunications Company - BTA (which is soon to be replaced by the Botswana Communications Regulatory Authority (BOCRA). According to the ITU (2009), there were 120000 Internet users as of September 2009 in Botswana. This represents $6 \%$ of Botswana's population which stands at 2065000 (US Census Bureau 2011). Considering the size of the country at $581730 \mathrm{~km}^{2}$, Botswana is sparsely populated. The ITU (2009) further ascertains that there were only 15000 Internet users in Botswana in the 
year 2000 representing $0.3 \%$ of the population at that time. Looking at this precedence of growth in Internet users, it is evident that it is quite likely that the number of Internet users will keep growing.

The BTA Annual report for 2010 (BTA 2010) puts the number of fixed line telephony subscribers in Botswana at 136593 users, whereas the number of mobile telephony subscribers is 2339029 users (this is because most of the subscribers would have more than two SIM cards from different mobile telecommunication service providers). Teledensity for fixed telephony subscribers is $8 \%$ whereas that for mobile subscribers is $105 \%$. Over the years, the growth of the fixed-line and mobile subscribers in Botswana has grown tremendously, from 150000 in 1997 to about 1800 000 subscribers in 2009, according to the BTA Annual Report (2009).

Botswana has a fairly developed ICT infrastructure (Isaacs 2007). This robust ICT infrastructure has led telecommunications service providers to offer adequately advanced services. The three mobile operators, Mascom Wireless, Orange Botswana, and BeMobile (subsidiary of the fixed-line monopoly operator, BTC, i.e. the Botswana Telecommunications Company) provide different ICT services such as $3 \mathrm{G}$ mobile, WiMAX, and bundling with fixed-line (ADSL) services. With the increase in mobile technology adoption, these services can help a myriad of ICT applications (such as e-Government, e-Learning, and e-Commerce) reach the marginal individuals in all corners of the country. In some instances, the ICT infrastructure is under-utilised with considerable disparity in the access to ICTs between the rural and urban areas. This can partly be attributed to the unreliable power supply, high cost of computers and computer gadgetry, lack of appropriate ICT skills and lack of local content on the Internet that would generate interest of the general citizenry (Isaacs 2007).

Hall and Lewin (2005:86) have outlined the importance of affluent policy in the efforts by the Botswana government towards the proliferation of ICT adoption and usage. Botswana has three main ICT policy cornerstones.

- To create an enabling environment for growth of ICT in the country.

- To provide universal service and access to information and communications facilities in the country with, for example, an Internet access point in every village.

- To make Botswana into a regional ICT hub so as to make the country's services sector globally competitive.

Apart from the aforementioned policy cornerstones, Botswana has put in place strategic initiatives to bridge the divide at various levels of the socio-economic hierarchy. Some of the pronounced initiatives that have been put in place will now be listed (Keakopa \& Bwalya 2010).

- The Maitlamo ICT policy was launched in 2005.

- The Universal Access (UA) and Universal Service (US) Policy aim to allow all citizens access ICT opportunities on equal basis.
- Foreseeable merging of the Tertiary Education Council and BOTA to push forward the Human Resource Development (HRD) strategy so as to usher in a competent human resource base to lead innovation strategies.

- Botswana Telecommunications Corporation (BTC) has successful completed the multi million Pula TransKalahari fibre optic project (approximately $2000 \mathrm{~km}$ ) for data, voice and electrical signal transmission.

- The BTC runs a rural communication programme that aims to connect 62 villages.

- The government has identified 3 Very Small Aperture Terminals (VSAT) sites comprising a Tele-Education Centre (learning Centre) at the University of Botswana (UB), a Tele-medicine Centre (Patient-end-terminal) at Nyangabgwe Referral Hospital in Northern District and a VVIP location at the office of the president.

- The BTC has a signatory status to three consortia that are intended to develop undersea optical fibre systems: the East Africa Submarine System (EASSY), to run alongside the eastern coast of Africa from Port Sudan through East African seaports down to Mtunzini in South Africa; the West Africa Festoon System (WAFS), intended to run alongside the western coast of Africa from Nigeria through Gabon and the DRC down to Angola, and possibly Namibia; and the Africa West Coast Cable (AWCC), proposed to run alongside the western coast of Africa from South Africa, Namibia through to the United Kingdom. It is anticipated that once these projects are completed, they will culminate into higher Internet and broadband penetration.

- The Nteletsa I \& II project by BTC aims to supply, install commission, and carry out operation and maintenance of network infrastructure in rural areas of Botswana.

- Tele-centers such as Community Access Centers (CAC) Kitsong - were initiated in 2006/07 to serve as a gateway to the Internet and access to other services in the rural areas.

- Large commitment has also been shown to encourage the use of ICTs in the public sector delivery frameworks in the form of electronic government (e-Government). To this effect, a participatory e-Government strategy meeting was convened to receive input in the working strategy document on e-Government roadmap from various stakeholders such as citizens, the private sector and the civil society.

- The Thuto.Net project strives to have enough computers linked to the Internet for all secondary and high schools, and later in primary schools in the country.

- The Ministry of Communication, Science and Technology launched a project known as i-Partnership aiming to empower government employees and unemployed youth to buy computers using government schemes.

- Recently, the Sesigo project has been implemented by the ACHAP together with co-operating partners to introduce the use of ICTs in public libraries.

All these projects are aimed at enhancing broadband connectivity and Internet penetration and therefore directly contributing to bridging the digital divide at the community, 
individual, and enterprise level in Botswana. The question however remains: are these interventions adequate given Botswana's vision to transform into a KBE? A look into the different interventions that have been put in place in the context of Korea may offer some comparative insights.

\section{Korea}

It is widely known that small countries such as Korea and Malaysia have shown impressive growth in ICT usage and innovation, and are therefore speedily delving towards establishing themselves as KBEs (Lee, O'Keefe \& Yun 2003; Wong \& Goh 2009). Massive deployment of ICTs in the various socio-economic frameworks was born out of the fact that Korea has limited natural resources and so it was necessary for it to move towards becoming a KBE for it to remain economical viable and competent. Korea has highly matured ICT penetration and currently boasts the world's highest per capita Internet and mobile penetration (Kang 2009), thanks to efforts dating back to the early 1990s. Lee, O'Keefe and Yun (2001) posit that Korea has a steadily privatised and fully liberalised ICT sector anchored on deregulated market principles.

Kang (2009) ascertains that Korea has kept intensifying its efforts to bridge the digital divide to put in place a peopleoriented and inclusive information society. By 2005, over 12 million citizens had access to broadband Internet and over $72 \%$ of the population was regular Internet users (Kang 2009). Kang (2009) also mentions that in 2001, mobile phone subscribers per 10000 persons were 2905 compared to 4427 in 2008. Within the same period, Internet banking subscribers constituted 1131 per 10000 people and 4694 in 2008. This demonstrates that access to ICTs has kept growing at a significant rate, thanks to dedicated initiatives.

The different digital divide initiatives and interventions in Korea were made with public-private-partnership (PPP) frameworks. The PPP consisted of over 679 individual members from different sectors of the economy. Kang (2009) articulates some of the major interventions put in place by the PPP arrangements in Korea such as a high speed information infrastructure project (1997); the 'Cyber Korea $21^{\prime}$ programme which focused on digital mobile migration and mobile Internet service (1999); the 'e-Korea Vision 2006' which laid the foundation of e-Government and initiated the world's first IMT-2000 service (third generation (3G) wireless technology for higher data rates between mobile phones and base antennas); the broadband convergence network $(\mathrm{BcN})$ implementation plan (2004); and the u-Sensor network and IPv6 Master Plan. The digital convergence era started in 2005 and saw the launch of terrestrial and satellite digital multimedia broadcasting (DMB) services. In 2006, there was transition towards the ubiquitous world, cemented by establishing the 'u-Korea Master Plan', and the launch of commercial services such as $\mathrm{BcN}$, WiBro, and HSDPA (Kang 2009). These interventions saw a surge in ICT access by ordinary citizens and the country being ranked top in the world by the Digital Opportunity Index
(DOI) criterion (Kang 2009). The Korean experience provides a case where utilisation of ICT in various socio-economic sectors such as in education was speedily adopted due to the cultural acceptance of the ICT phenomenon (Kim 2002). This positively impacted on the ICT diffusion process. Parents and pupils related to ICTs as a medium of education that had much potential for a promising future.

Because of the aforementioned interventions in promoting global broadband Internet access, Korea now leads the world in broadband Internet connections per capita and also has the highest WiFi hotspots per capita (currently at 55000 hotspots nationwide). According to a technical report by Freedom House (2011:2), in 2009, Korea had an estimated 39.4 million Internet users and in 2010 had over $80 \%$ of the households accessing broadband Internet. As of December 2010, there were 50.8 million mobile phone subscribers with more than $56 \%$ of these able to access Internet from their mobile phones.

Larger Internet penetration and usage, together with higher broadband penetration has culminated into Korea being highly innovative and efficient in a variety of its enterprise and national productivity value chains. For example, Korea is the largest shipbuilder in the world and is also the world's leading memory chip producer - indicating its technological competence and expertise (Kang 2009).

\section{Analysis of gaps and interventions}

A critical look at the two exploratory studies reveals that Korea started putting in place strategic initiatives towards effective bridging of different kinds of digital divides from the early 1990s. The situation in Botswana is a bit different in that these initiatives are just being authored at the moment. This entails that the benefits of these initiatives are not to be expected now but for some time in the near future. Looking at the Korean case, it is evident that the PPPs had the intention to bridge the digital divide using multiple approaches considering the fact that the digital divide is a multi-dimensional phenomenon. Korea implemented over 31 e-Government projects and enacted over 101 laws (Noh 2009) to make sure the institutional, legal and regulatory frameworks were in place before they started talking about fully transcending towards $\mathrm{KBE}$ or reducing the divide that existed between the rural and urban areas.

Botswana, however, is following a pragmatic approach, which entails that it aims to put in place a firm ICT infrastructure and policy background that will pave the way for carrying out robust implementation of ICT projects. This in itself is good but there are still disparities on ICT access and usage at individual levels. The largely identified vertical and horizontal gaps amongst different individuals is largely caused by lack of appropriate and adequate awareness campaigns on the benefits of active usage of computers and accessing the Internet to take advantage of the different socio-economic opportunities. Another major reason why there are a lot of disparities in the usage of computers and the Internet is that individuals may not have requisite and 
adequate ICT skills to effectively engage in ICT usage. The situation in Botswana is different from Korea because Koreans have a vibrant and world-class education system where ICT education is introduced right from the inception of the primary education curriculum and promotion campaigns for the benefits of ICT are more than adequate. To potentially bridge the vertical and horizontal divide in the case of Botswana, there is a need to introduce compulsory ICTs education in the curriculum and robust campaigns on all the feasible national communication channels on the benefits of ICTs.

Amongst some of the main endeavors of countries shifting their economies towards KBEs, the Korean approach has shown to be one of the most plausible examples regardless of where it is implemented. Thus it seems as though Botswana can use the Korean approach in its initiatives towards a KBE.

In order to make sure that the digital divide is reduced, Botswana should first implement background strategic initiatives, such as:

- putting in place robust institutional, legal and regulatory frameworks

- erecting appropriate ICT infrastructures

- developing relevant ICT skills of ordinary people

- establishing different rigorous ICT task-forces

- conducting substantial awareness campaigns.

It is anticipated that the aforementioned initiatives will go a long way in Botswana's pursuit towards a KBE.

\section{Conclusion}

There are many efforts that have been devoted towards fighting the intra-national digital divide in Botswana. This article has outlined the different principles of the digital divide and what tentative strategies have been implemented in Botswana. The Korean case is considered a noteworthy example of bridging the digital divide. In comparison to the Korean case, gaps are evident between the strategic initiatives and the approach for bridging the divide in Botswana. One of the very first steps towards bridging the intranational divide in Botswana is that it should promote broadband communication. This is in conformance with the premise that countries such as Korea, Malaysia, and Singapore - having introduced broadband communication - have seen their ICT uptake and innovation grow exponentially. The introduction of broadband will transcend into global accessibility of ICTs in the case of Botswana.

With the aforementioned strategies in place, full-fledged efforts towards transcending into a KBE can be established. As the empirical study has shown, the intra-national digital divide is evident in Botswana and this needs to be addressed before ambitious projects of establishing itself as a regional hub or transforming into a KBE can be pursued.

\section{Author acknowledgements}

The authors would like to thank the Ministry of Education, Botswana, who provided funding to the student (Nonofo) to facilitate this research as an undergraduate project aimed to understand the extent of the digital divide in Botswana.

\section{Author contributions}

Nonofo Sedimo was responsible for collecting the data, doing the preliminary data analysis and preliminary draft of this paper. This paper is part of her undergraduate final project, which she completed with a distinction.

\section{Author competing interest}

We declare that we have no financial or personal relationship(s) that may have inappropriately influenced us in writing this paper.

Bwalya Kelvin was responsible for coordinating the overall research process and paper writing. Prof. Du Plessis is a PhD supervisor for Kelvin and was responsible for ensuring that this paper achieves the adequate scholar rigor it has attained and was responsible for supervising the overall revision process upon obtaining peer review comments.

\section{References}

Bassey, C., 2008, 'Digital Money in a Digitally Divided World: Nature, Challenges and Prospects of ePayment Systems in Africa', paper presented at the Workshop on Everyday Digital Money: Innovation in Money Cultures and Technologies, University of California, Irvine, CA, 18-19th September

Bresnahan, T., Brynjolfsson, E. \& Hitt, L.M., 1999, 'Information technology, workplace organization, and the demand for skilled labor: Firm-level evidence', Working Paper No. 7136, National Bureau of Economic Research, Cambridge, MA.

Botswana Telecommunications Authority, 2009, Annual report 2009, viewed 22 May 2010 from, http://www.crasa.org/download.php?doc=doc_pub_eng44.pdf

Botswana Telecommunications Authority, 2010, Annual report of Botswana Telecommunications Authority (BTA), viewed 23 June 2011 from, www.crasa.org/ download.php?doc=doc_pub_eng44.pdf

Burke, A., Van Stel, A. \& Thurik, R., 2010, 'Blue Ocean vs Five Forces', Harvard Business Review 88(5), 28.

Campbell, D., 2001, 'Can the Digital Divide be Contained?', International Labour Review 140(2), 119-141. http//dx.doi.org/10.1111/j.1564-913X.2001.tb00217.x

Central Intelligence Agency, 2011, The World Fact Book, viewed 15 April 2011 from, https://www.cia.gov/library/publications/the-world-factbook/geos/bc.html.

Chon, K., 2001, 'The Future of the Internet Digital Divide', Communications of the ACM 44(3), 116. http//dx.doi.org/10.1145/365181.365231

Creswell, W.J., 1994, Research design: Qualitative and quantitative approaches, SAGE publications, London, UK.

Cronin, B., 2002, 'The Digital Divide', Library Journal 127(3).

Cullen, R., 2003, 'The Digital Divide; A Global and National Call to Action', The Electronic Library 21(3), 247-258. http//dx.doi.org/10.1108/02640470310480506

CWM, 2010, 'Second wave of sponsor, CRO growth hitting Asia-Pac', viewed 20 June 2011, from http://www.centerwatch.com/news-resources/sample/monthly/ cwm1702_20100201_CuOnLN.pdf

Freedom House, 2011, South Korea, viewed 12 October 2011, from www. freedomhouse.org/images/File/FotN/SouthKorea2011.pdf

Fuchs, C. \& Horak, E., 2008, 'Africa and the digital divide', Telematics and Informatics 25(2), 99-116. http//dx.doi.org/10.1016/j.tele.2006.06.004

Gambrill, S., 2010, 'Second wave of sponsor, CRO growth hitting Asia-Pac', The CenterWatch Monthly 17(2), February, 6-12, viewed 20 June 2011, from http:// www.centerwatch.com/news-resources/sample/monthly/cwm1702_20100201_ CuOnLN.pdf

Hall, R. \& Lewin, D., 2005, 'A final report to the Botswana Telecommunications Authority: ICT policies and liberalization', viewed 17 May 2010, from www.bta. org.bw/pubs/final\%20report\%20\%20-\%20liberalisation.doc

Hollensen, S., 2007, Global marketing: A decision oriented approach, 4th edn., Prentice Hall, Englewood Cliffs, NJ.

Isaacs, S., 2007, ICT in Education in Botswana, Survey of ICT and education in Africa: Botswana Country Report. Botswana - 1, viewed 18 February 2010, from www. infodev.org.

International Telecommunication Union, 2005, 'Measuring Digital Opportunity', WSIS Thematic meeting on Multi-Stakeholder Partnerships for Bridging the Digital Divide, Korea, Seoul, 23-24th June. 
International Telecommunications Union, 2006, Statistics, International Telecommunication Union, viewed 02 September 2011, from www.itu.int/ITU-D/ ict/statistics/

International Telecommunications Union, 2009, Botswana Internet Usage and Marketing Report, viewed 11 January 2011, from www.internetworldstats.com/ af/bw.htm.

Internet World Statistics, 2010, Internet users and population statistics for specific countries, viewed 16 August 2011, from www.internetworldstats.com

James, J., 2002, 'The digital divide between nations as international technological dualism', International Journal of Development Studies 1(2), 25-40.

James, J., 2003, Bridging the Global Digital Divide, Edward Elgar Publishing, Cheltenham, UK.

James, J., 2009, 'Measuring the global digital divide at the level of individuals', Current Science commentary $96(2), 25$.

Kang, B-S., 2009, 'Bridging the Digital Divide between Urban and Rural Areas: Experience of the Republic of Korea', IDD/TP-09-07 (Version 1.0.), Technical paper, ESCAP, Bangkok.

Keakopa, M.S. \& Bwalya, K.J., 2010, ,An Evaluation of ICT policy developments in Botswana', in E.E. Adomi (ed.), Handbook of Research on Information Communication Technology: Trends, Issues and Advancements, pp. 1-14, IG Global, Hershey.

Kettani, H., 2010, '2010 World Muslim Population', proceedings of the 8th Hawai International Conference on Arts and Humanities, Honolulu, Hawaii, January 12-16, 2010, viewed 24 June 2011 from www.pupr.edu/hkettani/papers/ HICAH2010.pdf

Kim, H-S., 2002, 'Sociological Analysis of 2002 Digital Formation of Korea', pape presented at the 2002 International Conference on the Digital Divide: Technology $\&$ Politics in the Information Age, David C. Lam Institute for East-West Studies, Hong Kong Baptist University, 22-23 August.

Kim, W.C. \& Mauborgne, R., 2004, 'Blue Ocean Strategy', Harvard Business Review 82(10), 76-84.

Lee, H., O'Keefe, R.M. \& Yun, Y., 2003, 'The Growth of Broadband and Electronic Commerce in Korea: Contributing Factors', The Information Society 19(1), 81-95. http//dx.doi.org/10.1080/01972240309470

Luk, S.C.Y., 2009, 'The impact of leadership and stakeholders on the success/failure of e-government service: Using the case study of e-stamping service in Hong Kong', Government Information Quarterly 26, 594-604. http//dx.doi.org/10.1016/j. giq.2009.02.009

Mansell, R., 2001, 'Digital Opportunities and the Missing Link for Developing Countries', Oxford Review of Economic Policy 17(2), 282-295. http//dx.doi. org/10.1093/oxrep/17.2.282

Mathuba, B.M., 2003, 'Ministry of Lands and Housing - Botswana', paper presented at an International Workshop on Land Policies in Southern Africa, Berlin, Germany, 26-27 May, viewed 21 June 2011, from www.fes.de/in_afrika/studien/Land Reform Botswana_Botselo_Mathuba.pdf

Noh, Y.K., 2009, ICT development in Korea, viewed 19 May 2010, from www.tiaonline. org/gov_affairs/events/Young_Noh_Presentation.pp
Norris, P., 2001, Digital divide: civic engagement, information poverty and the Internet worldwide, Cambridge University Press, Cambridge, UK

Organisation for Economic Co-operation and Development (OECD), 2004, Regulatory reform as a tool for bridging the Digital Divide, OECD, Paris.

Ono, H., 2005, 'Digital Divide in East Asia: Evidence from Japan, South Korea and Singapore', Working Paper Series 26, The International Centre for the Study of East Asian Development, Kitakyushu.

Robison, K. \& Crenshaw, E., 2000, 'Cyberspace and post-industrial transformations: A cross-national analysis of Internet development', paper presented at the Annua Meeting of the American Sociological Association, Washington, DC, 12-16th August.

Saunders, M., Lewis, P. \& Thornhill, A., 2002, Research methods for business students, 3rd edn., Prentice Hall, Harlow, UK.

Serrat, O., 2010, Knowledge solutions: tools, methods, and approaches to drive development forward and enhance its effects, Asian Development Bank, Mandaluyong City.

United Nations Department of Economics and Social Affairs, 2010, UN e-Government Survey: Leveraging e-government at a time of financial and economic crisis, viewed 04 October 2010, from http://unpan1.un.org/intradoc/groups/public/ documents/UN-DPADM/UNPAN038853.pdf

US Census Bureau, 2011, International Data Base - Botswana, viewed 19 June 2011 from www.census.gov/population/international/data/idb/country.php

Van der Meer, A. \& Van Winden, A., 2003, 'E-governance in cities', Regional Studies, 37(4), 407-419. http//dx.doi.org/10.1080/0034340032000074433

Venturelli, S., 2002, 'Inventing e-regulation in the US, EU and East Asia', Telematics and Informatics 19(2), 69-90. http//dx.doi.org/10.1016/S0736-5853(01)00007-7

Warschauer, M., 2001, 'Language, identity and the Internet', in B. Kolko, L. Nakamura, G. Rodman (eds.), Race in Cyberspace, pp. 208-231, Routledge, New York, NY.

Wilson, E.J., 2006, The Information Revolution and Developing Countries, MIT Press, Cambridge, MA

Wilson, M., 1996, 'Asking questions' in R. Sapsford \& V. Jupp (eds.), Data Collection and Analysis, p. 94, Sage, London, UK.

Wong, C-Y. \& Goh, K-L., 2009, 'Modeling the Self-Propagating Growth Function of Science and Technological Diffusion for Selected Asian Countries', Computer Science and Information Technology IEEE proceeding- IACSIT Advanced Science and Information Technology, IEEE proceeding- IACSIT Advanced 230.

World Bank Group, 2000, 'The networking revolution: Opportunities and challenges for developing countries', InfoDev Working Paper, Global Information and Communication Technologies Department, World Bank Group, Washington, DC., viewed 19 August 2011, from http://www.infodev.org/library/ NetworkingRevolution.pdf

Yin, R., 2003, Applications of Case Study Research, Sage Publications, London, UK.

Yoon, C-H., Na, K-Y., \& Jung, H-J., 2009, The Role of ICT in Economic Growth of Korea Productivity Changes across Industries since 1985, viewed 15 April 2011, from http://www2.wiwi.hu-berlin.de/wt1/studying/past courses/W08-09/The Role of_ICT(seminar).pdf 